\title{
Memory awareness in patients with Major Depressive Disorder
}

\author{
Tiago Mendes ${ }^{\text {a,b, }}$, Sandra Cardoso ${ }^{\text {a }}$, Manuela Guerreiro ${ }^{a}$, João Maroco ${ }^{c}$, Dina Silva ${ }^{\text {a,d }}$, \\ Luísa Alves ${ }^{\mathrm{e}}$, Ben Schmand ${ }^{\mathrm{f}}$, Frederico Simões do Couto ${ }^{\mathrm{a}} \mathrm{b}$, Maria Luísa Figueira ${ }^{\mathrm{a}}$, \\ Alexandre de Mendonça ${ }^{a}$ \\ ${ }^{\text {a }}$ Faculty of Medicine, University of Lisboa, Lisbon, Portugal \\ ${ }^{\mathrm{b}}$ Psychiatry and Mental Health Department, Santa Maria Hospital, Lisbon, Portugal \\ ${ }^{\mathrm{c}}$ Instituto Superior de Psicologia Aplicada, Lisbon, Portugal \\ ${ }^{\mathrm{d}}$ Cognitive Neuroscience Research Group, Department of Psychology and Educational Sciences and Centre for Biomedical Research (CBMR), Universidade do Algarve, \\ Faro, Portugal \\ ${ }^{\text {e }}$ Chronic Diseases Research Centre, NOVA Medical School, NOVA University of Lisbon, Portugal \\ ${ }^{\mathrm{f}}$ Faculty of Social and Behavioral Sciences, University of Amsterdam, the Netherlands
}

\section{A R T I C L E I N F O}

\section{Keywords:}

Major depression

Mild cognitive impairment

Alzheimer's disease

Subjective memory complaints

Awareness

Memory

\begin{abstract}
A B S T R A C T
Background: Subjective Memory Complaints (SMC) along with cognitive deficits are frequently observed in patients with Major Depressive Disorder (MDD). The relationship between SMC and objective memory performance in patients with MDD was evaluated, in comparison with patients with Mild Cognitive Impairment due to Alzheimer's Disease (MCI-AD) and healthy controls (HC).

Methods: Patients with MDD $(n=47)$, MCI-AD $(n=43)$ and HC $(n=45)$ were assessed with a self-report memory complaints scale (SMCS) and underwent a comprehensive clinical and neuropsychological assessment. A discrepancy score between the Logical Memory delayed recall and the SMCS total score was calculated as a measure of memory awareness.

Results: Patients with MDD (12.5 \pm 4.4$)$ and patients with MCI-AD (10.9 \pm 4.1$)$ had not significantly different SMCS total scores, whereas HC showed significantly lower scores (4.0 \pm 3.0$)$. As much as $74.5 \%$ of patients with MDD patients and $65.1 \%$ of patients with MCI-AD reported prominent memory complaints, whereas only $4.4 \%$ of HC did. Patients with MDD had relatively preserved memory tests, resulting in a higher discrepancy score than both patients with MCI-AD and HC. The SMCS total score correlated positively with depressive symptoms in the 3 groups of participants.

Conclusions: Patients with MDD showed inaccurate memory self-awareness as they under-estimated their memory functioning, a pattern distinct from both patients with MCI-AD and HC.
\end{abstract}

\section{Introduction}

Major Depressive Disorder (MDD) is a heterogeneous mental disease with high prevalence, affecting about $6 \%$ of the adult population worldwide each year (Otte et al., 2016). Changes in mood, motivation and affect are characteristic of MDD, but cognitive difficulties also represent a leading symptom (American Psychiatric Association, 2013). Slowing down of thought, diminished ability to think or concentrate and indecisiveness are included in the 5th edition of the Diagnostic and Statistical Manual of Mental Disorders (DSM-5) criteria for MDD (American Psychiatric Association, 2013). A systematic review and meta-analysis of 24 studies using the same battery of tests, the
Cambridge Neuropsychological Test Automated Battery (CANTAB), indicated that patients with MDD show cognitive deficits in the domains of executive functions, attention, and memory. Interestingly, these cognitive deficits persist beyond symptoms of low mood, during remitted states of depression (Rock et al., 2014). In accordance with the presence of cognitive deficits, patients with MDD frequently refer subjective memory complaints (SMC). Forty-three percent of the patients with MDD reported SMC assessed through a single question (Mowla et al., 2007). In another study, as much as $70 \%$ of the patients with MDD endorsed specific cognitive complaint themes (Miebach et al., 2017).

For sure, SMC are not specific of MDD. To start with, SMC are frequently reported by healthy adults (Ponds et al., 1997; Ginó et al.,

\footnotetext{
* Corresponding author. Faculty of Medicine, University of Lisbon, Av Prof Egas Moniz, 1649-028, Lisboa, Portugal.

E-mail address: tmendes@fm.ul.pt (T. Mendes).
} 
2010; Vlachos et al., 2019) as well as by people in the community who seek for primary clinical care (Waldorff et al., 2012). The association of SMC with depressive symptoms has been extensively documented in young and middle-aged individuals as well as in healthy elders (Jonker et al., 2000; Mendes et al., 2008; Balash et al., 2013). From another point of view, SMC may represent an important clinical symptom signalling an impending neurodegenerative disorder, namely Alzheimer's disease (AD). The presence of SMC may predict future cognitive decline (Reid and MacLullich, 2006) and a greater risk to develop dementia (Schmand et al., 1996; Mitchell et al., 2014). Recent revised diagnostic criteria that incorporate biomarkers maintain the report of memory decline by patients or informants as part of the core diagnostic features for $\mathrm{AD}$ (Dubois et al., 2007; Albert et al., 2011). Subjective memory complaints thus represent an important, albeit rather non-specific, symptom in clinical practice.

The SMC have been extensively studied in the context of $\mathrm{AD}$ and other neurodegenerative disorders, but less is known about the characteristics of SMC in patients with MDD. It was suggested that patients with MDD might report complaints qualitatively different from other disorders, namely expressing more attentional fluctuation and a stronger affective influence on memory (Miebach et al., 2017). In the present study, we used the SMC scale (SMCS), an instrument that comprises items representative of common memory complaints (Schmand et al., 1996) to characterize SMC in patients with MDD.

The relationship between the SMC and objective memory functioning has also raised a lot of interest. Patients with depression (most with MDD) and memory complaints indeed performed worse on objective memory tests as compared to depressed patients without memory complaints (Antikainen et al., 2001). However, Lahr et al. (2007) observed that patients with MDD reported cognitive problems in their everyday life that clearly exceed the deficits in the neuropsychological testing. The discrepancy between the report of cognitive problems in everyday life and impairment in neuropsychological tests might be attributed to increased distractibility to emotionally relevant stimuli present in the real world (Beblo et al. 2010). On the other hand, patients with MDD may exaggerate the memory complaints in relation to their objective memory performance, due to a negative cognitive bias and subsequent enhancement of the subjective sense of failure (Farrin et al. 2003). It is interesting that an opposite pattern might be observed in patients at early phases of $\mathrm{AD}$, who have pronounced objective memory deficits, and nevertheless may state a relatively favourable opinion about their cognitive capabilities reflecting anosognosia, that is, the loss of self-knowledge about cognitive deficits (Silva et al., 2014; Ryals et al., 2018).

In the present study, we investigated the SMC in patients with MDD. We aimed to know 1) the frequency of SMC; 2) the characteristics of SMC; 3) the relationship between SMC and objective memory performance in patients with MDD, in comparison with patients with early AD (MCI due to AD) and healthy controls (HC). We hypothesized that patients with MDD, by reporting SMC disproportionate to the objective memory performance, may show inaccurate memory self-awareness.

\section{Methods}

\subsection{Participants}

Participants were recruited in three distinct settings, all in the Lisbon area. Patients with MDD were followed at the outpatient clinic at the Department of Psychiatry and Mental Health, Centro Hospitalar Universitário de Lisboa Norte. Patients with aMCI-AD attended a memory clinic, Memoclínica. All patients were referred for and completed a comprehensive neuropsychological assessment, including the SMCS. HC were recruited at leisure centres, in the Lisbon area, that offer recreational, educational and well-being activities for senior people. The present study was conducted according to the declaration of Helsinki and was approved by the local ethics committee, the participants' informed consent was obtained before any procedure.

\subsubsection{Inclusion criteria}

2.1.1.1. Major Depressive Disorder. The diagnosis of MDD was established according to the Diagnostic and Statistical Manual of Mental Disorders (4th ed. Text rev. [DSM-IV-TR]; American Psychiatric Association, 2000).

The diagnosis of MDD was based on the patient's medical clinical records. An interview with the assistant psychiatrist was conducted to confirm the diagnosis and the medications prescribed at the time of the neuropsychological assessment, as well as clinical stability criteria, namely mood stabilization and no changes in medication in the three months prior to the neuropsychological assessment. Only outpatients clinically able to undergo through neuropsychological testing were included.

2.1.1.2. Mild Cognitive Impairment due to Alzheimer's disease. The diagnosis of MCI due to $\mathrm{AD}$ - high likelihood followed the criteria of the National Institute on Aging - Alzheimer's Association workgroups (Albert et al., 2011).

The diagnosis of MCI due to $\mathrm{AD}$ was established by an experienced neurologist (AdeM), after multidisciplinary consensus using all available clinical information.

2.1.1.3. Healthy controls. HC presented no cognitive complaints, maintained objective cognitive function and had preserved daily life independence.

\subsubsection{Exclusion criteria for all groups}

Presence of neurological disorders, namely stroke, brain tumor, significant head trauma, epilepsy; psychiatric disorders, namely MDD (except in the MDD group), schizophrenia and bipolar disorder; systemic illness with cognitive impact; history of alcohol abuse or recurrent substance abuse or dependence; seriously reduced vision or other sensory deficits likely to hinder assessment; presence of dementia according to the DSM-IV-TR or abnormal MMSE scores for the Portuguese population.

Detailed inclusion and exclusion criteria for all groups are described on supplementary material file.

\subsection{Measures}

\subsubsection{Neuropsychological assessment}

A comprehensive neuropsychological assessment was performed by the same group of trained neuropsychologists in each institution. The neuropsychological battery lasted from 45 to $60 \mathrm{~min}$ to be completed and comprised the following instruments:

1) Mini-Mental State Examination (MMSE) (Folstein et al. 1975). Normal values for the Portuguese population are $>27$ for more than 11 years of education and $>22$ for 11 or less years of education (Guerreiro et al., 1994).

2) Tests from the Battery of Lisbon for the Assessment of Dementia (Garcia, 1984; Guerreiro, 1998). This is a comprehensive neuropsychological battery, including tests from the Wechsler Memory Scale (Wechsler, 1945) and has been validated for the Portuguese population.

3) Geriatric Depression Scale (GDS; Yesavage et al., 1983; Sheik and Yesavage, 1986). The GDS is a self-report questionnaire that evaluates the existence of depressive symptomatology. For the present study, we used the short-form (15 items) of the self-report instrument, adapted for the Portuguese population (Barreto et al., 2008). 
4) Instrumental Activities of Daily Living (IADL; Lawton and Brody, 1969). The IADL is a tool that evaluates daily self-care activities. The Portuguese version was used (Pantoni et al., 2005).

\subsubsection{Subjective memory assessment}

The Subjective Memory Complaints Scale (SMCS) was used (Schmand et al., 1996). This scale comprises 10 individual items concerning difficulties in daily life memory tasks, considered representative of common memory complaints. Total scores range from 0 (absence of complaints) to 21 (maximal complaints score). The Portuguese version was used (Ginó et al., 2008). All participants completed the SMCS prior to the neuropsychological assessment.

\subsubsection{Estimate of memory awareness}

To study memory awareness in patients with MDD, patients with MCI-AD and HC, an index of discrepancy was calculated according to the formula [discrepancy score $=$ LM delayed recall ( $z$ score) minus -1 * SMCS total ( $z$ score)], following Vannini et al. (2017). The SMCS was multiplied by -1 because in SMCS a higher score means more memory complaints, whereas in the instrument used by Vannini et al. (2017), the Memory Functioning Questionnaire, a higher score corresponds to the absence of memory problems. In this way, the meaning of the discrepancy score is maintained according to the literature, that is, a lower score indicates over-estimation of memory functioning (these individuals believe they are functioning at a higher level than their objective memory performance would suggest), whereas a higher score indicates under-estimation of memory functioning (these individuals believe they are functioning less well than their objective performance would suggest) (Vannini et al., 2017).

\subsection{Statistical analysis}

Statistical analysis was performed using the IBM SPSS Statistics 26 for Windows (IBM Corp., Armonk, NY) package. The statistical significance threshold for all analyses was set at $p<0.05$.

Sample size was a priori estimated from a power analysis using the Power and Precision software (v.4; BioStat; Englewood, NJ). Using a one-way ANOVA model, recruitment of 45 participants in each group would allow detection of a medium size effect $(f=0.25)$ with power $=$ $73 \%$, and $\alpha=0.05$.

The $z$ scores for all neuropsychological variables, as well as for the SMCS with the purpose of obtaining discrepancy scores, were calculated according to the age and education norms for the Portuguese population with the equation $[z=(x$-mean $) / S D]$.

Data were checked for normality using the Shapiro-Wilk test and for homogeneity of variances using the Levene test. Since deviation from the normal distribution or the presence of heteroscedasticity were found for several variables, the non-parametric Kruskal-Wallis test, followed by the post hoc Dunn test, was used to assess differences in demographic, clinical and neuropsychological numeric data, discrepancy scores and SMCS scores. The analysis of the SMCS 10 items subscores was considered exploratory, and thus no correction for multiple comparisons being performed. When applicable, estimates of effect sizes were calculated using the $\eta^{2}$ test as described by Tomczak and Tomczak (2014). For categorical data Pearson $\chi^{2}$ tests were used followed by the post hoc $Z^{2}$ test for comparison of column proportions.

To know whether the 3 groups of participants could be statistically separated according to Logical Memory delayed recall ( $z$ score) values and the total SMCS ( $z$ score) values, a non-hierarchical clustering model was applied. The model used the Ward's Method with squared Euclidean distances, imposing a priori 3 clusters. The global percentage of correct classifications obtained with the clustering model was compared to the global percentage of correct classifications expected by chance alone. A model with $25 \%$ more correct classifications than the percentage expected by chance alone is considered to have good classificatory properties (Marôco, 2011).
To study the correlations between LM delayed recall, SMC total, discrepancy scores and relevant demographic and clinical variables, the bivariate Pearson correlation test was performed.

\section{Results}

\subsection{Demographic and neuropsychological data}

The study recruited 135 participants (MDD, $n=47$; MCI-AD, $n=43$; HC, $n=45)$. The demographic and clinical characteristics are shown in Table 1. Patients with MDD were younger and more often female when compared to the MCI-AD and HC. Both patients with MDD and HC were less educated than patients with MCI-AD. Patients with MCI-AD had lower MMSE score as compared to the other groups.

\subsection{Neuropsychological assessment}

The results of the comprehensive neuropsychological assessment are shown in Table 2. As expected, patients with MCI-AD had poorer performances in tests of memory (Word Recall and Logical Memory immediate and delayed recall) and orientation, as well as verbal initiative (Semantic Verbal Fluency). Patients with MDD performed worse in a test of attention (Digit Span Forward).

\subsection{Subjective memory complaints}

Patients with MDD $(12.5 \pm 4.4)$ and patients with MCI-AD (10.9 \pm 4.1) had high and not significantly different SMCS total scores, whereas HC had significantly lower scores $(4.0 \pm 3.0)$ (Table 3$)$. As much as $74.5 \%$ of patients with MDD patients and $65.1 \%$ of patients with MCI$\mathrm{AD}$ reported prominent memory complaints (SMCS total $z$ score above 1.5 according to age and education norms), whereas only $4.4 \%$ of $\mathrm{HC}$ did. An exploratory analysis of the SMCS individual items was performed. Patients scored higher than HC in all items, except item 7, Did you ever lose your way in the neighborhood?, a seldom reported complaint. Patients with MDD had higher scores than patients with MCI-AD in three SMCS items.

\subsection{Awareness of memory}

Awareness of memory functioning was assessed by calculating an index based on discrepancy scores between objective memory performance (Logical Memory delayed recall, $z$ score) and subjective memory report (SMCS total, $z$ score). Patients with MDD showed higher discrepancy scores than both patients with MCI-AD and HC, which did not significantly differ (Fig. 1). Similar results were obtained when calculating the discrepancy scores as the difference between the $z$ scores of Word Recall and SMCS (results not shown).

To understand better this discrepancy between objective performance and subjective memory report, the Logical Memory delayed recall ( $z$ score) values and the total SMCS ( $z$ score) values were plotted in a Cartesian graph, where the 3 groups of participants appear segregated (Fig. 2). In fact, an unsupervised clustering procedure classified $71.1 \%$ of the cases coincidently with the 3 groups of participants, whereas the expected percentage of correct classifications obtained by chance would be only $33.4 \%$. HC had good memory performance and few SMC, patients with MCI-AD showed poor memory performance and many SMC, and patients with MDD also reported many SMC but had better memory performance than patients with MCI-AD.

\subsection{Correlations between demographic characteristics, SMCS and neuropsychological data}

There were no significant correlations between age and education with the main variables of interest of the present study, namely, Logical Memory delayed recall score, SMCS total score, and the discrepancy 
Table 1

Demographic and clinical characteristics of patients with MDD, patients with MCI-AD and healthy controls.

\begin{tabular}{|c|c|c|c|c|c|c|}
\hline & \multirow{2}{*}{$\frac{\mathrm{MDD}}{n=47}$} & \multirow{2}{*}{$\frac{\text { MCI-AD }}{n=43}$} & \multirow{2}{*}{$\frac{\mathrm{HC}}{n=45}$} & \multicolumn{3}{|c|}{ Statistical significance } \\
\hline & & & & Statistics & $p$-value & Post hoc \\
\hline Age at first assessment, years, mean (SD) & $59.3(8.7)$ & $68.5(7.0)$ & $65.9(8.2)$ & $\mathrm{H}=27.591$ & $<0.001$ & MDD < MCI-AD, HC \\
\hline Gender, male/female, $n$ (\% female) & $7 / 40(85)$ & $15 / 28(65)$ & $24 / 21(47)$ & $\chi^{2}=15.140$ & 0.001 & MDD $>$ MCI-AD, HC* \\
\hline Education, years, mean (SD) & $7.8(4.7)$ & $12.7(3.6)$ & $7.6(5.0)$ & $\mathrm{H}=29.978$ & $<0.001$ & HC, MDD < MCI-AD \\
\hline MMSE, mean (SD) & $28.4(1.0)$ & $26.3(1.9)$ & $28.9(1.3)$ & $\mathrm{H}=42.550$ & $<0.001$ & MCI-AD < MDD, HC \\
\hline GDS, mean (SD) & $9.4(3.5)$ & $4.2(2.8)$ & $2.5(2.6)$ & $\mathrm{H}=52.236$ & $<0.001$ & $\mathrm{HC}<\mathrm{MCI}-\mathrm{AD}<\mathrm{MDD}$ \\
\hline \multicolumn{7}{|l|}{ Medication, n (\%) } \\
\hline Antidepressants & $40(85.1)$ & $18(41.9)$ & & & & \\
\hline Mood stabilizers & $5(10.6)$ & & & & & \\
\hline Antipsychotics & $6(12.8)$ & $1(2.3)$ & & & & \\
\hline Benzodiazepines & $34(72.3)$ & $9(20.9)$ & & & & \\
\hline Acetylcholinesterase inhibitors & & $9(20.9)$ & & & & \\
\hline Memantine & & $1(2.3)$ & & & & \\
\hline
\end{tabular}

Abbreviations: MDD = Major Depressive Disorder; MCI-AD = Mild Cognitive Impairment due to Alzheimer's Disease; HC=Healthy Controls; MMSE = Mini-Mental State Examination; GDS = Geriatric Depression Scale; SD = standard deviation.

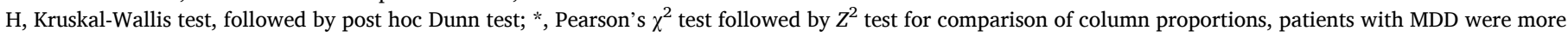
often females compared to patients with MCI-AD and healthy controls. Statistically significant values (p $<0.05)$ in bold.

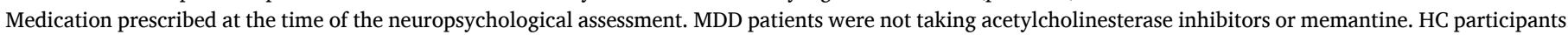
were not taking antidepressants, antipsychotic drugs, acetylcholinesterase inhibitors or memantine.

Table 2

Neuropsychological performances in patients with MDD, patients with MCI-AD and healthy controls.

\begin{tabular}{|c|c|c|c|c|c|c|c|}
\hline \multirow[b]{2}{*}{ Cognitive domains } & \multirow[b]{2}{*}{ MDD } & \multirow[b]{2}{*}{ MCI-AD } & \multirow[b]{2}{*}{ HC } & \multicolumn{4}{|c|}{ Statistical significance } \\
\hline & & & & Statistics & $p$-value & Effect size & Post hoc \\
\hline Cognitive tests & $n=47$ & $n=43$ & $n=45$ & $\mathrm{H}$ & & $\eta^{2}$ & \\
\hline \multicolumn{8}{|l|}{ Attention and Executive functions } \\
\hline Digit Span Forward & $-0.16(1.22)$ & $0.86(1.40)$ & $1.85(1.53)$ & 39.80 & $<0.001$ & 0.29 & $\mathrm{MDD}<\mathrm{MCI}-\mathrm{AD}<\mathrm{HC}$ \\
\hline Digit Span Backward & $-0.02(1.60)$ & $0.08(0.90)$ & $0.88(2.03)$ & 4.68 & 0.096 & 0.02 & NS \\
\hline \multicolumn{8}{|l|}{ Verbal Initiative } \\
\hline Semantic Verbal Fluency & $0.62(1.54)$ & $-0.52(1.76)$ & $0.35(1.22)$ & 11.16 & 0.004 & 0.07 & MCI-AD < MDD, HC \\
\hline \multicolumn{8}{|l|}{ Reasoning } \\
\hline Raven CPM & $0.08(0.92)$ & $-0.30(1.35)$ & $0.50(0.80)$ & 7.24 & 0.027 & 0.04 & MCI-AD $<$ HC \\
\hline \multicolumn{8}{|l|}{ Memory } \\
\hline Word Recall & $0.52(1.12)$ & $-2.06(1.57)$ & $-0.36(1.10)$ & 56.70 & $<0.001$ & 0.41 & $\mathrm{MCI}-\mathrm{AD}<\mathrm{HC}<\mathrm{MDD}$ \\
\hline Logical Memory (immediate recall) & $-0.60(1.07)$ & $-1.63(1.12)$ & $0.35(0.81)$ & 51.92 & $<0.001$ & 0.38 & MCI-AD $<$ MDD $<$ HC \\
\hline Logical Memory (delayed recall) & $-0.58(0.99)$ & $-1.55(1.10)$ & $0.55(0.64)$ & 64.20 & $<0.001$ & 0.47 & MCI-AD $<$ MDD $<$ HC \\
\hline Orientation & $-0.38(2.03)$ & $-5.13(4.35)$ & $0.43(0.16)$ & 58.55 & $<0.001$ & 0.43 & MCI-AD $<$ MDD, HC \\
\hline
\end{tabular}

Abbreviations: $\mathrm{MDD}=$ Major Depressive Disorder; MCI-AD = Mild Cognitive Impairment due to Alzheimer's Disease; HC=Healthy Controls; CPM=Colored Progressive Matrices; NS=Non-significant.

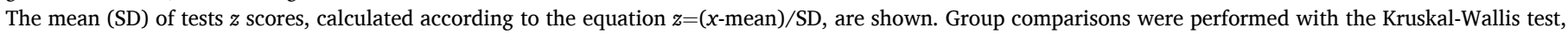
followed by post hoc Dunn test. Statistically significant values $(p<0.05)$ in bold.

score (Table 4).

The SMCS total score correlated positively with the depressive symptoms evaluated by GDS in the three groups, that is, participants with depressive symptoms generally reported more SMC (Table 4). This correlation might also have driven the correlation between GDS and the discrepancy score, of which the SMCS total score is component, and in a similar manner the Logical Memory delayed recall score appeared correlated with the discrepancy score, of which it is the other component.

\section{Discussion}

The main findings of the present study are that patients with MDD frequently and heavily report SMC, however they have relatively preserved memory tests, resulting in discrepancy between subjective memory complaints and objective memory performance. In other words, patients with MDD show inaccurate memory self-awareness because they under-estimate their memory functioning.

It might be the prominent SMC in patients with MDD have been accentuated by a referral bias, and would not be generalizable, in the sense that patients with MDD followed at the outpatient clinic might have been referred for comprehensive neuropsychological assessment because of more pronounced cognitive complaints. However, the present results are consistent with the high frequency of SMC in patients with MDD reported in previous studies, as much as $70 \%$ of the patients with MDD endorsing specific cognitive complaint themes (Miebach et al., 2017). Admittedly, the frequency of SMC may depend on whether a single question or a full questionnaire is used to elicit the report of SMC, as well as on the choice of different questionnaires (Vogel et al., 2016).

The profile of SMC in patients with MDD was not very different from those reported by patients with MCI-AD. Patients with MDD would score even higher than patients with MCI-AD in a few individual SMCS items, like item 4, Do you often forget where things are left and item 10, Do you have concentration problems?. It is interesting to note that these individual SMCS items might involve not only mnestic but also attentional capabilities. The presence of diminished ability to think or concentrate is acknowledged in the clinical criteria for MDD (American Psychiatric Association, 2000). Beblo et al. (2010) suggested that the discrepancy between the report of cognitive problems in everyday life and the relative preservation of neuropsychological tests in patients with MDD could be attributed to increased distractibility to emotionally relevant stimuli present in the real world. A previous study found that attention difficulties were the most prominent cognitive symptom reported by 
Table 3

Subjective memory complaints in patients with MDD, patients with MCI-AD and healthy controls.

\begin{tabular}{|c|c|c|c|c|c|c|}
\hline & \multirow{2}{*}{$\begin{array}{l}\text { MDD } \\
\overline{n=47}\end{array}$} & \multirow{2}{*}{$\begin{array}{l}\text { MCI- } \\
\frac{\mathrm{AD}}{n=43}\end{array}$} & \multirow{2}{*}{$\begin{array}{l}\mathrm{HC} \\
\overline{n=45}\end{array}$} & \multicolumn{3}{|c|}{ Statistical significance } \\
\hline & & & & $\mathrm{H}$ & $p$-value & $\begin{array}{l}\text { Post } \\
\text { hoc }\end{array}$ \\
\hline $\begin{array}{l}\text { SMC1, mean (SD) } \\
\text { Do you have any } \\
\text { complaints } \\
\text { concerning your } \\
\text { memory? }\end{array}$ & $\begin{array}{l}2.17 \\
(0.76)\end{array}$ & $\begin{array}{l}2.23 \\
(0.72)\end{array}$ & $\begin{array}{l}0.89 \\
(0.61)\end{array}$ & 59.97 & $<0.001$ & $\begin{array}{l}\text { MDD, } \\
\text { MCI- } \\
\mathrm{AD}> \\
\mathrm{HC}\end{array}$ \\
\hline $\begin{array}{l}\text { SMC2 Do other } \\
\text { people find you } \\
\text { forgetful? }\end{array}$ & $\begin{array}{l}1.32 \\
(0.63)\end{array}$ & $\begin{array}{l}1.16 \\
(0.57)\end{array}$ & $\begin{array}{l}0.42 \\
(0.58)\end{array}$ & 41.50 & $<0.001$ & $\begin{array}{l}\text { MDD, } \\
\text { MCI- } \\
\mathrm{AD}> \\
\mathrm{HC}\end{array}$ \\
\hline $\begin{array}{l}\text { SMC3 Do you ever } \\
\text { forget names of } \\
\text { family members } \\
\text { or friends? }\end{array}$ & $\begin{array}{l}1.51 \\
(1.02)\end{array}$ & $\begin{array}{l}1.21 \\
(0.96)\end{array}$ & $\begin{array}{l}0.29 \\
(0.59)\end{array}$ & 36.82 & $<0.001$ & $\begin{array}{l}\text { MDD, } \\
\text { MCI- } \\
\mathrm{AD}> \\
\mathrm{HC}\end{array}$ \\
\hline $\begin{array}{l}\text { SMC4 Do you often } \\
\text { forget where } \\
\text { things are left? }\end{array}$ & $\begin{array}{l}2.09 \\
(0.77)\end{array}$ & $\begin{array}{l}1.67 \\
(0.94)\end{array}$ & $\begin{array}{l}0.71 \\
(0.69)\end{array}$ & 47.42 & 0.046 & $\begin{array}{l}\text { MDD } \\
>\text { MCI- } \\
\mathrm{AD}> \\
\mathrm{HC}\end{array}$ \\
\hline $\begin{array}{l}\text { SMC5 Do you often } \\
\text { use notes to } \\
\text { avoid forgetting } \\
\text { things? }\end{array}$ & $\begin{array}{l}1.17 \\
(0.79)\end{array}$ & $\begin{array}{l}1.33 \\
(0.71)\end{array}$ & $\begin{array}{l}0.60 \\
(0.65)\end{array}$ & 21.31 & 0.001 & $\begin{array}{l}\text { MDD, } \\
\text { MCI- } \\
\mathrm{AD}> \\
\mathrm{HC}\end{array}$ \\
\hline $\begin{array}{l}\text { SMC6 Do you ever } \\
\text { have difficulties } \\
\text { in finding } \\
\text { particular } \\
\text { words? }\end{array}$ & $\begin{array}{l}0.85 \\
(0.36)\end{array}$ & $\begin{array}{l}0.63 \\
(0.49)\end{array}$ & $\begin{array}{l}0.31 \\
(0.47)\end{array}$ & 27.92 & 0.032 & $\begin{array}{l}\text { MDD } \\
>\text { MCI- } \\
\mathrm{AD}> \\
\mathrm{HC}\end{array}$ \\
\hline $\begin{array}{l}\text { SMC7 Did you ever } \\
\text { lose your way in } \\
\text { neighborhood? }\end{array}$ & $\begin{array}{l}0.11 \\
(0.31)\end{array}$ & $\begin{array}{l}0.09 \\
(0.29)\end{array}$ & $\begin{array}{l}0.07 \\
(0.25)\end{array}$ & 0.46 & 0.795 & NS \\
\hline $\begin{array}{l}\text { SMC8 Do you think } \\
\text { more slowly than } \\
\text { you used to? }\end{array}$ & $\begin{array}{l}1.00 \\
(0.63)\end{array}$ & $\begin{array}{l}0.84 \\
(0.48)\end{array}$ & $\begin{array}{l}0.29 \\
(0.51)\end{array}$ & 34.77 & $<0.001$ & $\begin{array}{l}\text { MDD, } \\
\text { MCI- } \\
\mathrm{AD}> \\
\mathrm{HC}\end{array}$ \\
\hline $\begin{array}{l}\text { SMC9 Do your } \\
\text { thoughts ever } \\
\text { become } \\
\text { confused? }\end{array}$ & $\begin{array}{l}1.00 \\
(0.55)\end{array}$ & $\begin{array}{l}0.88 \\
(0.66)\end{array}$ & $\begin{array}{l}0.20 \\
(0.46)\end{array}$ & 42.95 & $<0.001$ & $\begin{array}{l}\text { MDD, } \\
\text { MCI- } \\
\mathrm{AD}> \\
\mathrm{HC}\end{array}$ \\
\hline $\begin{array}{l}\text { SMC10 Do your } \\
\text { thoughts ever } \\
\text { become } \\
\text { confused? }\end{array}$ & $\begin{array}{l}1.23 \\
(0.67)\end{array}$ & $\begin{array}{l}0.91 \\
(0.65)\end{array}$ & $\begin{array}{l}0.27 \\
(0.54)\end{array}$ & 42.86 & 0.047 & $\begin{array}{l}\mathrm{MDD} \\
>\mathrm{MCI}- \\
\mathrm{AD}> \\
\mathrm{HC}\end{array}$ \\
\hline $\begin{array}{l}\text { SMC, total, mean } \\
\quad \text { (SD) }\end{array}$ & $\begin{array}{l}12.45 \\
(4.4)\end{array}$ & $\begin{array}{l}10.91 \\
(4.0)\end{array}$ & $\begin{array}{l}4.02 \\
(3.0)\end{array}$ & 65.82 & $<0.001$ & $\begin{array}{l}\text { MDD, } \\
\text { MCI- } \\
\mathrm{AD}> \\
\mathrm{HC}\end{array}$ \\
\hline
\end{tabular}

Abbreviations: $\mathrm{SMC}=$ Subjective Memory Complaints; $\mathrm{SD}=$ standard deviation; MDD = Major Depressive Disorder; MCI-AD = Mild Cognitive Impairment due to Alzheimer's Disease; $\mathrm{HC}=$ Healthy Controls; $\mathrm{NS}=$ Non significant.

Scoring of items 1, 3, and 4: 0: no; 1: yes, but no problem; 2: yes, problem; 3: yes, serious problem.

Scoring of items 2 and 5: 0: no; 1: yes, sometimes; 2: yes, often.

Scoring of items 6 and 7: 0: no; 1: yes.

Scoring of items 8, 9 and 10: 0: no; 1: yes; 2: yes, serious problem.

Group comparisons were performed with the Kruskal-Wallis test, followed by post hoc Dunn test.

Statistically significant values $(p<0.05)$ in bold.

patients with MDD (Srisurapanont et al., 2018).

In the present study, patients with MDD indeed performed poorly, even worse than patients with MCI-AD, in attentional tasks, namely the Digit Span Forward. A systematic review and meta-analysis demonstrated that significant moderate deficits in attention (rapid visual information processing) and executive functions (spatial working memory) and to a lesser extent memory (paired associated learning), represent a core and clinically relevant feature of depression that persists beyond symptoms of low mood in patients with MDD (Rock et al., 2014). A meta-analysis concluded that cognitive deficits in euthymic

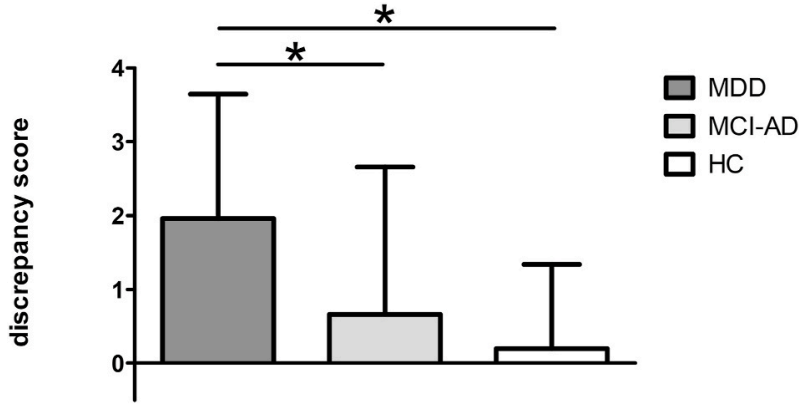

Fig. 1. Comparison of memory self-awareness in patients with MDD, patients with MCI-AD and healthy controls.

Abbreviations: MDD = Major Depression Disorder; MCI-AD = Mild Cognitive Impairment due to Alzheimer's Disease; $\mathrm{HC}=$ Healthy Controls.

Discrepancy scores between objective memory performance and subjective memory complaints (mean and SD) are depicted. Patients with MDD patients had higher discrepancy scores than patients with MCI-AD and healthy controls. Group comparisons were performed with the Kruskal-Wallis test, followed by post hoc Dunn test. ${ }^{*} p<0.05$.

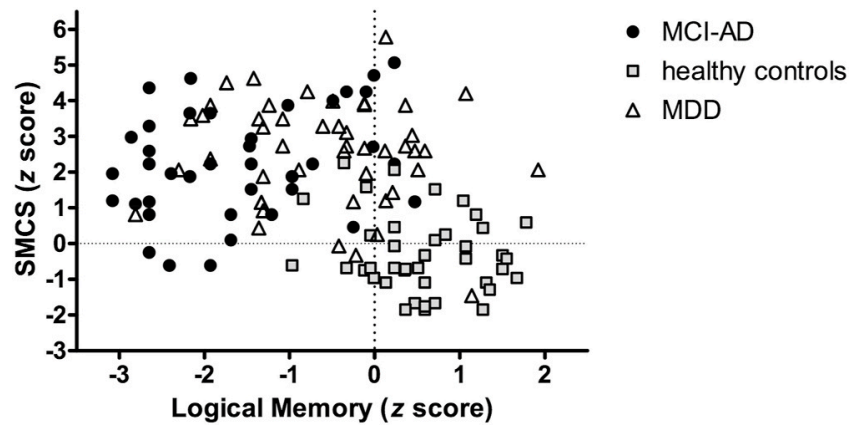

Fig. 2. Cartesian graph of participants in reference to subjective memory report and objective memory performance.

Abbreviations: SMCS=Subjective Memory Complaints scale, $z$ score; Logical Memory $=$ Logical Memory delayed recall, $z$ score; MCI-AD = Mild Cognitive Impairment due to Alzheimer's Disease; MDD = Major Depressive Disorder.

patients with MDD are generally modest, with more pronounced deficits in executive functions, particularly inhibitory control (Bora et al., 2012). Accordingly, in the present study patients with MDD were not as affected as patients with MCI-AD in the domains of memory, orientation, verbal fluency and reasoning. Nonetheless, cognitive dysfunction does represent a core feature of MDD (DSM-5, American Psychiatric Association, 2013; Naguy et al., 2020), and treatment of cognitive deficits experienced by patients with MDD may contribute to improve functional outcomes (Pan et al., 2019).

The main finding of the present study is that patients with MDD showed a distinctive relationship between SMC and objective memory performance. Thus, HC had good memory performance and few SMC, patients with MCI-AD showed poor memory performance and many SMC, whereas patients with MDD also reported many SMC but had better memory performance than patients with MCI-AD. The implications for awareness of memory functioning, measured by discrepancy scores between objective memory scores (Logical Memory delayed recall) and subjective memory scores (SMCS), are straightforward. Awareness of memory, for different reasons, was quite good in HC, who correctly appraised to have good memory, and in patients with MCI-AD, who had memory complaints and poor memory performance. In contrast, awareness of memory turned out to be quite inadequate in patients with MDD, who heavily reported memory complaints in face of a relatively preserved memory performance. Importantly, we now show that the level of memory awareness is able to distinguish patients with 
Table 4

Correlations between LM delayed recall, SMC total, discrepancy score and the demographic and clinical variables.

\begin{tabular}{|c|c|c|c|c|c|c|c|}
\hline & & \multicolumn{2}{|c|}{ LM delayed recall } & \multicolumn{2}{|c|}{ SMCS total } & \multicolumn{2}{|c|}{ Discrepancy score } \\
\hline & & $\mathrm{r}$ & $p$-value & $\mathrm{r}$ & $p$-value & $\mathrm{r}$ & $p$-value \\
\hline \multirow[t]{3}{*}{ Age } & MDD & -0.063 & 0.674 & -0.130 & 0.385 & 0.150 & 0.315 \\
\hline & MCI-AD & 0.170 & 0.275 & -0.207 & 0.183 & -0.059 & 0.705 \\
\hline & $\mathrm{HC}$ & -0.137 & 0.371 & 0.032 & 0.837 & -0.048 & 0.752 \\
\hline \multirow[t]{3}{*}{ Education } & MDD & 0.164 & 0.271 & 0.049 & 0.744 & 0.139 & 0.352 \\
\hline & MCI-AD & 0.257 & 0.096 & -0.028 & 0.857 & 1.116 & 0.457 \\
\hline & $\mathrm{HC}$ & 0.113 & 0.462 & -0.162 & 0.288 & -0.084 & 0.584 \\
\hline \multirow[t]{3}{*}{ MMSE } & MDD & 0.025 & 0.882 & 0.066 & 0.698 & 0.069 & 0.685 \\
\hline & MCI-AD & 0.532 & 0.001 & 0.130 & 0.449 & 0.395 & 0.017 \\
\hline & $\mathrm{HC}$ & 0.430 & 0.003 & -0.129 & 0.398 & 0.125 & 0.412 \\
\hline \multirow[t]{3}{*}{ GDS } & MDD & -0.102 & 0.567 & 0.352 & 0.041 & 0.210 & 0.232 \\
\hline & MCI-AD & 0.141 & 0.378 & 0.529 & $<0.001$ & 0.463 & 0.002 \\
\hline & $\mathrm{HC}$ & -0.132 & 0.393 & 0.546 & $<0.001$ & 0.426 & 0.004 \\
\hline \multirow[t]{3}{*}{ DS Forward } & MDD & 0.148 & 0.321 & -0.070 & 0.641 & 0.027 & 0.859 \\
\hline & MCI-AD & -0.014 & 0.929 & -0.031 & 0.843 & -0.030 & 0.848 \\
\hline & $\mathrm{HC}$ & 0.032 & 0.833 & -0.163 & 0.285 & -0.130 & 0.394 \\
\hline \multirow[t]{3}{*}{ LM delayed recall } & MDD & & & -0.098 & 0.512 & 0.504 & $<0.001$ \\
\hline & MCI-AD & & & 0.241 & 0.120 & 0.709 & $<0.001$ \\
\hline & $\mathrm{HC}$ & & & -0.145 & 0.342 & 0.433 & 0.003 \\
\hline \multirow{3}{*}{ Semantic Verbal Fluency } & MDD & 0.092 & 0.540 & -0.132 & 0.377 & -0.061 & 0.686 \\
\hline & MCI-AD & 0.307 & 0.045 & 0.238 & 0.125 & 0.336 & 0.027 \\
\hline & $\mathrm{HC}$ & 0.070 & 0.649 & 0.116 & 0.446 & 0.146 & 0.340 \\
\hline
\end{tabular}

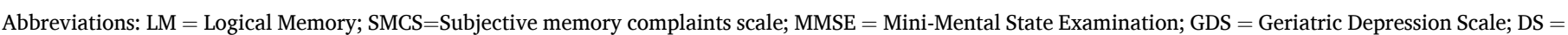

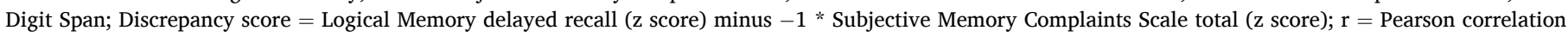
coefficient. Statistically significant values $(p<0.05)$ in bold.

MDD not only from patients with MCI, as reported by Coutinho et al. (2016), but also from HC. It interesting to note that a previous study from Vannini and co-workers showed altered memory self-awareness in patients with MCI-AD, who would overestimate their memory function (Vannini et al., 2017). It is recognized that patients at early phases of AD may suffer from anosognosia, that is, the loss of self-knowledge about cognitive deficits (Ryals et al., 2018). In the present study, patients with MCI-AD appeared to maintain awareness of their memory deficits. At an early phase of their neurodegenerative trajectory, patients may be able to capture and even overestimate the changes in memory that they are experiencing (Vannini et al., 2017), and it is plausible that awareness of memory in patients with MCI-AD might vary in different studies depending on the inclusion of early or late patients with MCI-AD, or the specific tests used for the calculation of the index of awareness.

The reasons for the discrepancy between subjective memory complaints and objective memory performance in patients with MDD are worthwhile debating. Patients with MDD may have a negatively biased perception (Beck, 1967), leading to a pessimistic neurocognitive appraisal (Mohn and Rund, 2016; Schweizer et al., 2018). Another possible explanation may be the characteristic of intrusive and ruminative negative thoughts might distract these patients more in their everyday life environments than in the context of a comprehensive neuropsychological assessment (Petersen et al., 2019). In accordance, self-reports of severe memory difficulties in everyday life situations clearly surpass objective memory performance in standard laboratory settings (Beblo et al., 2017; Schwert et al., 2018). In other words, the ecological validity of the neuropsychological assessment tests may not capture entirely the difficulties of everyday life tasks (Lahr et al., 2007).

The feebleness of the association between SMC and objective memory performance is recognized (Gagnon et al., 1994; Jungwirth et al., 2004). Accordingly, in the present study no associations between SMC and objective memory performance were found in the HC, patients with MCI-AD and patients with MDD. The absence of association between SMC and objective memory performance in healthy individuals has been repeatedly reported (Mendes et al., 2008; Schwert et al., 2018). Regarding patients with MCI, SMC were weakly associated with objective memory performance and more strongly related to mood problems (Yates et al., 2017). Also Seo et al. (2017) showed that the association between SMC and objective memory is largely mediated by the presence of depressive symptoms in patients with prodromal AD. Concerning patients with MDD, no associations between SMC and objective cognitive deficits were generally found in different studies (Farrin et al., 2003; Mohn and Rund, 2016; Srisurapanont et al., 2017; Schwert et al., 2018).

The importance of the association between SMC and depressive symptoms also merits a word. In the present study, it was consistently observed in HC, patients with MCI-AD and patients with MDD. The influence of depressive symptoms, but not age, gender or education, on the SMCS scores in healthy people was previously emphasised (Mendes et al., 2008). Also, Schweizer and co-workers showed a relationship between depressive symptoms and self-reported memory problems in a large healthy population cohort, even when controlling for variations in age, cognitive ability and gender (Schweizer et al., 2018). A systematic review mentioned depression as one of the most important factors associated with SMC (Brigola et al., 2015). In patients with MCI, the association of SMC and depressive symptoms has been documented in many studies collected in the meta-analysis of Mitchell (2008). Specifically in patients fulfilling criteria for MCI-AD, a recent study confirmed the association between SMC and depressive symptoms (Mendes et al., 2019). In patients with mood disorders, subjective memory is also negatively influenced by the presence of depressive symptoms, both in bipolar disorder (Miskowiak et al., 2016) and in MDD (Srisurapanont et al., 2017; Serra-Blasco et al., 2019). Thus, the relationship between SMC and depressive symptoms appears quite consistent in different populations evaluated.

To the best of our knowledge, this is the first study to investigate the relationship between SMC and objective cognitive performance when comparing at the same time patients with MDD, patients with MCI-AD and HC. A few other strengths may be pointed out. First, the assessment of SMC was made through a structured self-report questionnaire and the comprehensive neuropsychological evaluation was made by the same group of trained neuropsychologists. Second, the diagnosis of MDD was made by experienced psychiatrists, and the diagnosis and the medication prescribed at the time of the assessment were confirmed through contact with the respective assistant psychiatrist. In third place, the diagnosis of MCI-AD was made by the same neurologist with large experience in neurodegenerative diseases, following international criteria based on $\mathrm{AD}$ biomarkers. A few limitations must also be recognized. Some unbalance among the groups regarding gender and 
education was observed, however this would not influence the results, since comparisons were performed with $z$ scores adjusted to age and education, and no correlations between these demographic factors and either objective memory or SMCS were found in any group. Another limitation is that we cannot exclude that some participants with MDD, or even HC, might have positive AD biomarkers, eventually at a preclinical stage of AD. Still another limitation is the use of medication at the time of the neuropsychological assessment in the clinical groups, that would be unethical to discontinue.

In conclusion, patients with MDD show inaccurate memory selfawareness because they frequently and heavily report SMC while keeping relatively preserved memory tests, in contrast to patients with MCI-AD and healthy controls. Differential diagnosis between MDD and MCI-AD is a difficulty sometimes faced by clinicians (Coutinho et al., 2016). Although we found differences in memory awareness between the two conditions, it is at present unclear whether memory awareness might be clinically useful to discriminate between MDD and MCI-AD.

\section{Declaration of competing interestCOI}

All authors declare no conflicts of interest.

\section{Acknowledgements}

The authors thank Memoclínica for the facilities provided and Dr. Catarina Alvarez for collaboration in neuropsychological testing. This work was supported by a grant from Fundação para a Ciência e Tecnologia (FCT) -PTDC/MED-NEU/27946/2017. The funding institution had no role in the study design, data collection and analysis, decision to publish, or preparation of the manuscript.

\section{Appendix A. Supplementary data}

Supplementary data to this article can be found online at https://doi. org/10.1016/j.jpsychires.2021.03.016.

\section{References}

Albert, M.S., Dekosky, S.T., Dickson, D., Dubois, B., Feldman, H.H., Fox, N.C., Gamst, A., Holtzman, D.M., Jagust, W.J., Petersen, R.C., Snyder, P.J., Carrillo, M.C., Thies, B., Phelps, C.H., 2011. The diagnosis of mild cognitive impairment due to Alzheimer's disease: recommendations from the National Institute on Aging and Alzheimer's Association workgroup. Alzheimers Dement 7, 270-279.

American Psychiatric Association, 2000. Diagnostic and Statistical Manual of Mental Disorders DSM-IV-TR, fourth ed. APA, Washington, DC. text revision.

American Psychiatric Association, 2013. Diagnostic and Statistical Manual of Mental Disorders, DSM-5. APA $5^{\text {th }}$ Edition., Washington, DC.

Antikainen, R., Hanninen, T., Honkalampi, K., Hintikka, J., Koivumaa-Honkanen, H., Tanskanen, A., et al., 2001. Mood improvement reduces memory complaints in depressed patients. Eur. Arch. Psychiatr. Clin. Neurosci. 251, 6-11.

Balash, Y., Mordechovich, M., Shabtai, H., Giladi, N., Gurevich, T., Korczyn, A.D., 2013. Subjective memory complaints in elders: depression, anxiety, or cognitive decline? Acta Neurol. Scand. 127, 344-350.

Barreto, J., Leuschner, A., Santos, F., Sobral, M., 2008. Geriatric depression scale (GDS). Grupo de Estudos de Envelhecimento Cerebral e Demência. In: Mendonça, A., Guerreiro, M. (Eds.), Escalas e Testes na Demência, third ed., pp. 71-72 Lisboa.

Beblo, T., Mensebach, C., Wingenfeld, K., Schlosser, N., Rullkoetter, N., Schaffrath, C., Driessen, M., 2010. The impact of neutral and emotionally negative distraction on memory performance and its relation to memory complaints in major depression. Psychiatr. Res. 178, 106-111.

Beblo, T., Kater, L., Baetge, S., Driessen, M., Piefke, M., 2017. Memory performance of patients with major depression in an everyday life situation. Psychiatr. Res. 248, $28-34$.

Beck, A.T., 1967. Depression: Clinical, Experimental and Theoretical Aspects. Harper and Row, New York.

Bora, E., Harrison, B.J., Yücel, M., Pantelis, C., 2012. Cognitive impairment in euthymic major depressive disorder: a meta-analysis. Psychol. Med. 43, 2017-2026.

Brigola, A., Manzini, C., Oliveira, G., Ottaviani, A., Sako, M., Vale, F., 2015. Subjective memory complaints associated with depression and cognitive impairment in the elderly: a systematic review. Dement Neuropsychol. 9, 51-57.

Coutinho, G., Drummond, C., Teldeschi, A., Mattos, P., 2016. Awareness of memory deficits is useful to distinguish between depression and mild cognitive impairment in the elderly. Rev. Bras. Psiquiatr. 38, 231-234.
Dubois, B., Feldman, H.H., Jacova, C., Dekosky, S.T., Barberger-Gateau, P., Cummings, J., Delacourte, A., Galasko, D., Gauthier, S., Jicha, G., Meguro, K, O'brien, J., Pasquier, F., Robert, P., Rossor, M., Salloway, S., Stern, Y., Visser, P.J., Scheltens, P., 2007. Research criteria for the diagnosis of Alzheimer's disease: revising the NINCDS-ADRDA criteria. Lancet Neurol. 6, 734-746.

Farrin, L., Hull, L., Unwin, C., Wykes, T., David, A., 2003. Effects of depressed mood on objective and subjective measures of attention. J. Neuropsychiatry Clin. Neurosci. 15, 98-104.

Folstein, M.F., Folstein, S., McHugh, P.R., 1975. Mini-Mental State: a practical method for grading the cognitive state of patients for the clinician. J. Psychiatr. Res. 12, 189-198.

Gagnon, M., Dartigues, J.F., Mazaoux, J.M., Dequae, L., Letenneur, L., Giroire, J.M. Braberger-Gateau, P., 1994. Self-reported memory complaints and memory performance in elderly French community residents: results of the PAQUID research program. Neuroepidemiology 13, 145-154.

Garcia, C., 1984. Doença de Alzheimer, problemas do diagnóstico clínico. Tese de Doutoramento. Faculdade de Medicina de Lisboa.

Ginó, S., Guerreiro, M., Garcia, C., 2008. Subjective memory complaints (QSM). In: Mendonça, Ad, Guerreiro, M. (Eds.), Escalas e Testes na Demência, 2 ed. Grupo de Estudos de Envelhecimento Cerebral e Demência, Lisbon, pp. 117-120.

Ginó, S., Mendes, T., Maroco, J., Ribeiro, F., Schmand, B.A., de Mendonça, A., Guerreiro, M., 2010. Memory complaints are frequent but qualitatively different in young and elderly healthy people. Gerontology 56, 272-277.

Guerreiro, M., 1998. Contributo da Neuropsicologia para o Estudo das Demências. Dissertação de Doutoramento em Ciências Biomédicas. Faculdade de Medicina de Lisboa.

Guerreiro, M., Silva, A.P., Botelho, A., Leitão, O., Castro-Caldas, A., Garcia, C., 1994. Adaptação à população portuguesa da tradução do Mini Mental State Examination (MMSE). Rev. Port Neurol. 1, 9-10.

Jonker, C., Geerlings, M.I., Schmand, B., 2000. Are memory complaints predictive for dementia? A review of clinical and population based studies. Int. J. Geriatr. Psychiatr. 15, 983-991.

Jungwirth, S., Fischer, P., Weissgram, S., Kirchmeyr, W., Bauer, P., Tragl, K.-H., 2004 Subjective memory complaints and objective memory impairment in the ViennaTransdanube aging community. JAGS 52, 263-268.

Lahr, D., Beblo, T., Hartje, W., 2007. Cognitive performance and subjective complaints before and after remission of major depression. Cognit. Neuropsychiatry 12, 25-45.

Lawton, M.P., Brody, E.M., 1969. Assessment of older people: self-maintaining and instrumental activities of daily living. Gerontol. 9, 179-186.

Marôco, J., 2011. Análise Estatística Com O SPSS Statistics. 5. Pero Pinheiro, Portugal.

Mendes, T., Cardoso, S., Guerreiro, M., Maroco, J., Silva, D., Alves, L., Schmand, B. Gerardo, B., Lima, M., Santana, I., de Mendonça, A., 2019. Can subjective memory complaints identify $\mathrm{A} \beta$ positive and $\mathrm{A} \beta$ negative amnestic mild cognitive impairment patients? J. Alzheim. Dis. 70, 1103-1111.

Mendes, T., Ginó, S., Ribeiro, F., Guerreiro, M., Sousa, G., Ritchie, K., de Mendonça, A., 2008. Memory complaints in healthy young and elderly adults: reliability of memory reporting. Aging Ment. Health 12, 177-182.

Miebach, L., Wolfsgruber, S., Frommann, I., Buckley, R., Wagner, M., 2017. Different cognitive complaint profiles in memory clinic and depressive patients. Am. J. Geriatr. Psychiatr. 26, 463-475.

Miskowiak, K.W., Petersen, J.Z., Ott, C.V., Knorr, U., Kessing, L.V., Gallagher, P., Robinson, L., 2016. Predictors of the discrepancy between objective and subjective cognition in bipolar disorder: a novel methodology. Acta Psychiatr. Scand. 134, 511-521.

Mitchell, A.J., 2008. The clinical significance of subjective memory complaints in the diagnosis of mild cognitive impairment and dementia: a meta-analysis. Int. J. Geriatr. Psychiatr. 11, 1191-1202.

Mitchell, A.J., Beaumont, H., Fergusson, D., Yadegarfar, M., Stubbs, B., 2014. Risk of dementia and mild cognitive impairment in older people with subjective memory complaints: meta-analysis. Acta Psychiatr. Scand. 1-13.

Mohn, C., Rund, B.R., 2016. Neurocognitive profile in major depressive disorders: relationship to symptom level and subjective memory complaints. BMC Psychiatr. $16,108$.

Mowla, A., Ashkani, H., Ghanizadeh, A., Dehbozorgi, G.R., Sabayan, B., Chohedri, A.H., 2007. Do memory complaints represent impaired memory performance in patients with major depressive disorder? Depress. Anxiety 25, 92-96.

Naguy, A., Moodliar-Rensburg, S., Alamiri, B., 2020. Cognitive symptoms domain in major depressive disorder-revisited. Asian J. Psychiatr. 53, 102216.

Otte, C., Gold, S.M., Penninx, B.W., Pariante, C.M., Etkin, A., Fava, M., Mohr, D.C., Schatzberg, A.F., 2016. Major depressive disorder. Nat. Rev. Dis. Prim. 2, 16065.

Pan, Z., Park, C., Brietzke, E., Zuckerman, H., Rong, C., Mansur, R.B., McIntyre, R.S., 2019. Cognitive impairment in major depressive disorder. CNS Spectr. 24, 22-29.

Pantoni, L., Basile, A.M., Pracucci, J., Asplund, K., Bogousslavsky, J., Chabriat, H., Inzitari, D., on behalf of the LADIS study group, 2005. Impact of age related cerebral white matter changes on the transition to disability - the LADIS study: rationale, design and methodology. Neuroepidemiology 24, 51-62.

Petersen, J.Z., Porter, R.J., Miskowiak, K.W., 2019. Clinical characteristics associated with the discrepancy between subjective and objective impairment in depression. J. Affect. Disord. 246, 763-774.

Ponds, R.W.H.M., Commisaris, K.J.A.M., Jolles, J., 1997. Prevalence and covariates of subjective forgetfulness in a normal population in The Netherlands. Int. J. Aging Hum. Dev. 45, 207-221.

Reid, L.M., Maclullich, A.M., 2006. Subjective memory complaints and cognitive impairment in older people. Dement. Geriatr. Cognit. Disord. 22, 471-485.

Rock, P.L., Roiser, J.P., Riedel, W.J., Blackwell, A.D., 2014. Cognitive impairment in depression: a systematic review and meta-analysis. Psychol. Med. 44, 2029-2040. 
Ryals, A.J., O’Neill, J.T., Mesulam, M.M., Weintraub, S., Voss, J.L., 2018. Memory awareness disruptions in amnestic mild cognitive impairments: comparison of multiple awareness types for verbal and visuospatial material. Neuropsychol. Dev. Cogn. B Aging Neuropsychol. Cogn. 1-22.

Schmand, B., Jonker, C., Hoojier, C., Lindeboom, J., 1996. Subjective memory complaints may announce dementia. Neurology 46, 121-125.

Schweizer, S., Kievit, R., Emery, T., Henson, R., 2018. Symptoms of depression in a large healthy population cohort are related to subjective memory complaints and memory performance in negative contexts. Psychol. Med. 48, 104-114.

Schwert, C., Stohrer, M., Aschenbrenner, S., Weisbrod, M., Schröder, A., 2018. Biased neurocognitive self-perception in depressive and in healthy persons. J. Affect. Disord. 232, 96-102.

Seo, E.H., Kim, H., Choi, K.Y., Lee, K.H., Choo, I.H., 2017. Association of subjective memory complaint and depressive symptoms with objective cognitive functions in prodromal Alzheimer's disease including pre-mild cognitive impairment. J. Affect. Disord. 217, 24-28.

Serra-Blasco, M., Torres, I.J., Vicent-Gil, M., Goldberg, X., Navarra-Ventura, G., Aguilar, E., Via, E., Portella, M.J., Figuereo, I., Palao, D., 2019. Discrepancy between objective and subjective cognition in major depressive disorder. Eur. Neuropsychopharmacol 29, 46-56.

Sheik, J.I., Yeasavage, J.A., 1986. Geriatric Depression Scale (GDS): recent evidence and development of a shorter version. In: Brink, T.L. (Ed.), Clinical Gerontology: A Guide to Assessment and Intervention. The Harworth Press Inc., NY, pp. 165-173.

Silva, D., Guerreiro, M., Faria, C., Maroco, J., Schmand, B.A., de Mendonça, A., 2014. Significance of subjective memory complaints in the clinical setting. J. Geriatr. Psychiatr. Neurol. 27, 259-265.

Srisurapanont, M., Mok, Y.M., Yang, Y.K., Chan, H.-N., Della, C.D., Zainal, N.Z., Kalita, P., 2018. Cognitive complaints and predictors of perceived cognitive dysfunction in adults with major depressive disorder: findings from the Cognitive
Dysfunction in Asians with Depression (CogDAD) study. J. Affect. Disord. 232, 237-242.

Srisurapanont, M., Suttajit, S., Eurviriyanukul, K., Varnado, P., 2017. Discrepancy between objective and subjective cognition in adults with major depressive disorder. Sci. Rep. 7, 3901.

Tomczak, M., Tomczak, E., 2014. The need to report effect size estimates revisited. An overview of some recommended measures of effect size. Trends Sport Sci. 1, 9-25.

Vannini, P., Amariglio, R., Hanseeuw, B., Johnson, K.A., McLaren, D.G., Chhatwal, J., Pascual-Leone, A., Rentz, D., Sperling, R.A., 2017. Memory self-awareness in the preclinical and prodromal stages of Alzheimer's disease. Neuropsychologia 99, 343-349.

Vlachos, G.S., Cosentino, S., Kosmidis, M.H., Anastasiou, C.A., Yannakoulia, M., Dardiotis, E., Hadjigeorgiu, G., Sakka, P., Ntanasi, E., Scarmeas, N., 2019. Prevalence and determinants of subjective cognitive decline in a representative Greek elderly population. Int. J. Geriatr. Psychiatr. 34, 846-854.

Vogel, A., Salem, L.C., Andersen, B.B., Waldemar, G., 2016. Differences in quantitative methods for measuring subjective cognitive decline - results from a prospective memory clinic study. Int. Psychogeriatr. 28, 1513-1520.

Waldorff, F.B., Siersma, V., Vogel, A., Waldemar, G., 2012. Subjective memory complaints in general practice predicts future dementia: a 4-year follow-up study. Int. J. Geriatr. Psychiatr. 27, 1180-1188.

Wechsler, D., 1945. Wechsler Memory Scale. Psychological Corporation, San Antonio, TX, US.

Yates, J.A., Clare, L., Woods, R.T., MRC, C.F.A.S., 2017. Subjective memory complaints, mood and MCI: a follow up study. Aging Ment. Health 21, 313-321.

Yesavage, J.A., Brink, T.L., Rose, T.L., Lum, O., Huang, V., Adey, M., Leirer, V.O., 1983. Development and validation of a geriatric depression screening scale: a preliminary report. J. Psychiatr. Res. 17, 37-49. 